\section{O Plano Diretor como instrumento de planejamento e gestão urbana dos centros emergentes no Norte de Minas/MG.}

The city's Master Plan as an instrument for planning and urban management of the emerging cities in the North of Minas Gerails/Brazill.

\section{Brenda Melo Bernardes*, Marcos Esdras Leite**}

*Graduada em Arquitetura e Urbanismo pelo Centro Universitário Metodista Izabela Hendrix (2011). Especialista em Sistemas Tecnológicos e Sustentabilidade Aplicados ao Ambiente Construído - UFMG (2013). Mestre em Arquitetura e Urbanismo - Escola de Arquitetura - UFMG (2016). Doutoranda em Arquitetura e Urbanismo - Escola de Arquitetura - UFMG, brenda.mbernardes@gmail.com

**Professor do Departamento de Geociências Universidade Estadual de Montes Claros-UNIMONTES. Professor do Programa de Pós-Graduação em Geografia/ UNIMONTES e do Programa de Pós-Graduação em Desenvolvimento Social/ UNIMONTES. Doutor em Geografia pela Universidade Federal de Uberlândia - UFU. Coordenador do Laboratório de Geoprocessamento/UNIMONTES. Bolsista de produtividade da FAPEMIG. Coordenador da Câmara de Ciências Aplicadas da FAPEMIG, marcosesdrasleite@gmail.com
Relações Intermunicipais

Políticas públicas.

Desenvolvimento local e regional.

\section{Keywords:}

Socio-cultural practices.

Public policies.

\section{Palavras-chave:}

Local and Regional Development.
Resumo

gestão municipal, contudo, apesar da sua relevância e planejamento e para cidades com mais de 20.000 habitantes, na prática presencia-se, em muitos municípios, a dificuldade da sua implementação e de articulação das diretrizes propostas com o desenvolvimento local. No Norte de rência de investimentos públicos na mesorregião e pela necessidade de fortalecimento das relações intermunicipais para obtenção de recursos orçamentários de entes federais e estatais. Desse modo, pretende-se por meio deste artigo compreender a influência que os princípios de ordenamento do solo e as políticas de educação e saúde, explicitadas nos planos diretores, exercem no desenvolvimento dos centros emergentes no Norte de Minas. Sobre os métodos de pesquisa adota-se a abordagem qualitativa com a utilização de pesquisa bibliográfica e documental. Minas, objeto de estudo desse artigo, essa situação é agravada pela ca- usjt

\section{arq.urb}

número 30 |jan-abr de 2021 Recebido: 09/04/2020 Aceito: $03 / 11 / 2020$ 


\section{Introdução}

A associação de Estados e municípios em Mesorregiões (Figura 1), de acordo com os critérios definidos pelo IBGE (2017), tem como objetivo contribuir para o direcionamento de investimentos e no processo de gestão pública a partir da análise das condições de articulações ou fragmentações do território, o que favorece a constituição de base de dados estatísticos relativos às regiões geográficas instituídas. Assim, a definição das mesorregiões e microrregiões e, posteriormente, sua revisão para Regiões Geográficas Intermediárias e Imediatas, visam fornecer subsídios para o planejamento urbano nas esferas federal e estadual, por meio da definição de critérios metodológicos de análises socioespaciais (IBGE, 2017).

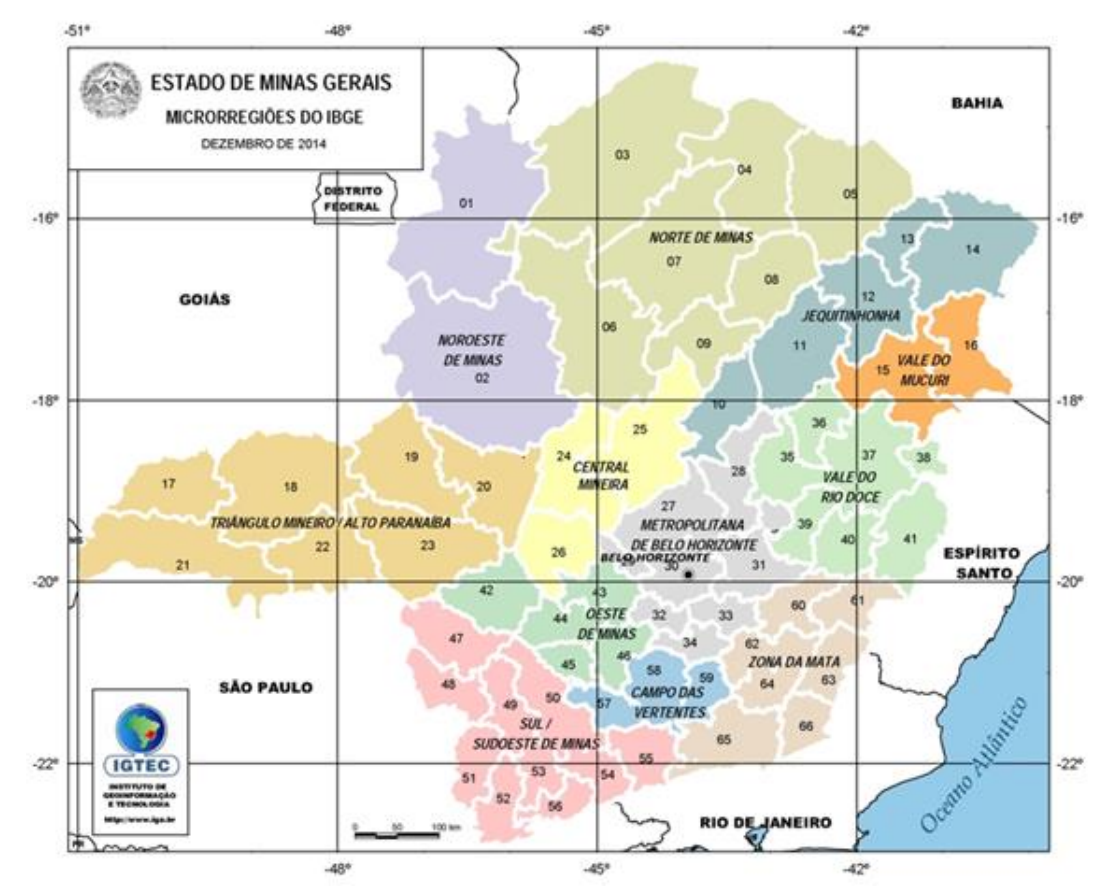

Figura 1: Mesorregiões instituídas de acordo com os critérios do IBGE. Fonte: IBGE, 2014.

O Estado de Minas Gerais, de acordo com o IBGE (2017), é subdividido em 12 mesorregiões, dentre as quais se destaca a Mesorregião do Norte de Minas, foco de estudo do artigo. A Mesorregião do Norte de Minas teve como um dos critérios de demarcação o princípio de agrupamento de municípios por similaridades sob os aspectos social, natural e econômico. Ademais, pode-se dizer que a disparidade de investimentos no processo de industrialização das regiões que compõe o Estado de Minas Gerais, destacando-se a valorização das porções Central, Sul e Oeste em detrimento à marginalização das regiões Norte e Nordeste, foram fatores determinantes na definição do recorte espacial dessa mesorregião em questão, seguindo os indicadores socioeconômicos (PEREIRA; HESPANHOL, 2015).

Nesse contexto, é importante mencionar que a Mesorregião do Norte de Minas ocupa uma posição de isolamento socioeconômico quando comparada às demais mesorregiões que compõem o Estado de Minas Gerais. Tal fator, associado à segregação socioespacial, desigualdade econômica e dificuldade na obtenção de investimentos públicos a partir de recursos provenientes da União e do Estado (PEREIRA, 2007) elucidam a importância do processo de gestão integrada para estímulo ao desenvolvimento urbano regional no Norte de Minas.

Recentemente, o IBGE (2017) atribuiu nova classificação para as Mesorregiões e Microrregiões instituídas que passaram a ser denominadas como Regiões Geográficas Intermediárias e Regiões Geográficas Imediatas. Assim, as regiões geográficas de influência intermediária são aquelas que desempenham um papel de articulação da rede urbana superior às regiões de influência imediata, pelo maior número de fluxos que comporta e pela diversidade de serviços ofertados, recebendo classificação de metrópole ou capital regional. Essas regiões geográficas ocupam a posição intermediária entre as Unidades de Federação e as regiões de influência imediata. Já as Regiões Geográficas Imediatas exercem menor capacidade de influência na rede urbana, sendo constituídas por no mínimo 5 e no máximo 25 municípios, e configuram centros urbanos referência para suprir as necessidades básicas da população que integram a rede de influência (CASTRO, 2017).

No Norte de Minas, Montes Claros é o município que sobressai como Região Geográfica de Influência Intermediária, apresentando importância primária na rede urbana pelo maior dinamismo dos fluxos que estabelece entre os demais municípios que integram a rede urbana e por constituir uma centralidade regional devido à concentração de comércios, instituições de ensino superior, pela oferta de trabalho e de serviços essenciais como de saúde. Além disso, a centralidade se destaca 
devido ao porte populacional, formado por uma população total (urbana e rural) de 404.804 habitantes - dados estimados pelo IBGE para o ano de 2018, o que influencia na sua classificação como cidade de porte médio. Essa importância do município no âmbito regional, associado à carência de recursos para atendimento das demandas por serviços públicos dos municípios de menor porte que integram essa mesorregião, tem intensificado as relações intermunicipais e de dependência do Norte de Minas em relação ao centro regional de Montes Claros.

No que tange ao processo de planejamento e gestão dos municípios que integram o Norte de Minas, é importante destacar a utilização Plano Diretor como instrumento para direcionar o desenvolvimento local. A lei municipal tornou-se obrigatória para cidades com mais de 20.000 habitantes a partir das diretrizes da Constituição Federal de 1988 e da regulamentação do Estatuto da Cidade em 2001, entretanto, apesar da sua importância para o desenvolvimento local, muitos municípios ainda não dispõe da lei e, quando elaborada, verifica-se o distanciamento entre o discurso, enquanto constitui plano, e a prática, entendida como o processo de gestão.

O Plano Diretor é reconhecido como um importante instrumento que orienta o processo de gestão local e o desenvolvimento dos municípios. Sobre sua relevância, Saboya $(2007$, p. 37) ressalta que: "[...] o plano diretor representa o principal elo entre planejamento e gestão. É ele quem deve orientar as ações da gestão, a partir das discussões e deliberações realizadas durante o processo de planejamento." Souza (2008) enfatiza as diferenças entre o planejamento e gestão, apesar de serem conceitos complementares, ao colocar que:

O planejamento é a preparação para a gestão futura, buscando-se evitar ou minimizar problemas e ampliar margens de manobra; e a gestão é a efetivação, ao menos em parte (pois o imprevisível e o indeterminado estão sempre presentes, o que torna a capacidade de improvisação e a flexibilidade sempre imprescindíveis), das condições que o planejamento feito no passado ajudou a construir. Longe de serem concorrentes ou intercambiáveis, planejamento e gestão são distintos e complementares (SOUZA, 2008, p.46).

Assim, é importante mencionar nesse contexto que, enquanto o planejamento resulta na elaboração de um plano que visa orientar o futuro desenvolvimento urbano de uma localidade, a gestão, ao contrário do planejamento, tem caráter permanente, já que caracteriza o processo contínuo de deliberações pelo poder público (SABOYA, 2007). Nesse sentido, torna-se fundamental que as diretrizes expressas no plano diretor sejam elaboradas ancoradas na participação popular e em um contexto específico (SOUZA, 2008).

De acordo com pesquisas realizadas pelo IBGE (2016) sobre as Grandes Regiões e as Unidades da Federação, da totalidade de 5.570 municípios somente 2.786 possuem plano diretor e 691 encontra-se em fase de elaboração. Ademais, considerando o somatório dos municípios que dispõe de plano diretor e dos que estão em fase de elaboração, constata-se que $37,6 \%$ dos municípios brasileiros ainda não tem se comprometido com o seu desenvolvimento. Essa situação é mais agravante para municípios com população inferior à 20.000 habitantes, que atinge o percentual de $52,1 \%$ sem plano diretor. Nesse sentido, apesar da relevância do Plano Diretor, reforçada historicamente por meio da promulgação da Constituição Federal de 1988 e da regulamentação do Estatuto da Cidade em 2001, que concedeu maior autonomia municipal e tornou obrigatória a sua elaboração para cidades com mais de 20.000 habitantes, na prática, o que se verifica é que grande parte dos municípios de menor porte ainda não dispõe da lei municipal, e quando elaborada, muitos gestores não a utilizam como instrumento efetivo de planejamento urbano.

Nesse sentido, diante das limitações de implementação dos planos diretores municipais e das demandas de desenvolvimento e de investimentos públicos que caracterizam a Mesorregião, o artigo tem como objetivo geral compreender a influência dos princípios de ordenamento do solo e das políticas de educação e saúde no desenvolvimento dos centros emergentes situados no Norte de Minas.

De acordo com estudos conduzidos por Amorim Filho; Rigotti e Campos (2007), os centros urbanos emergentes seriam as cidades que se enquadram na faixa de transição entre pequeno e médio porte, predominando população urbana inferior à 50.000 habitantes e com demandas de estruturação econômica. Desse modo, no Norte de Minas, esses centros desempenham papel secundário de conexão regional já que, apesar de não ocuparem posição mais elevada na hierarquia da rede urbana em questão (Montes Claros é o município que comporta maior número de conexões na rede urbana do Norte de Minas), constituem importantes subcentralidades, influenciando nas conexões estabelecidas com as pequenas cidades do seu entorno.

Ainda em relação aos objetivos do artigo em questão, define-se como específicos: (1) caracterizar brevemente a Mesorregião do Norte de Minas e suas regiões 
intermediária e imediatas, conforme classificações e dados do IBGE (2010); (2) analisar os critérios e desafios que envolvem a instituição do Plano Diretor como instrumento de planejamento e gestão a partir de um comparativo entre os planos diretores dos municípios selecionados como objetos de estudo.

Assim, pretende-se, por meio desse artigo, contribuir para estimular o conhecimento da mesorregião do Norte de Minas e dos centros emergentes que a compõem. Considera-se importante a realização desse estudo já que o Norte de Minas carece de produção científica direcionada para os municípios que ocupam papel secundário na rede urbana, as pesquisas são realizadas, sobretudo, em relação a Montes Claros, cidade de porte médio1. Ainda, é relevante a condução desta pesquisa para elucidar o papel do Plano Diretor no processo de planejamento e gestão, bem como, a necessidade de instituição de política públicas integradas para articulação das demandas locais e regionais no processo de desenvolvimento urbano do Norte de Minas.

No que tange à metodologia de pesquisa, adota-se a abordagem qualitativa e recorre-se a pesquisa teórica e documental. Para tanto, será proposta a análise sobre a importância dos planos diretores e seus desafios e entraves, a partir da consulta de artigos e livros que tratam sobre o processo de gestão local. No enfoque quantitativo, serão utilizados como fonte de consulta também os dados do IBGE (2010) para caracterização dos municípios sobre os aspectos populacionais, de educação e saúde.

Ademais, o artigo será estruturado em duas partes. Na primeira seção será apresentada a caracterização da Mesorregião do Norte de Minas e a análise dos centros emergentes. Essa abordagem tem como intuito contextualizar a Mesorregião foco de estudo e compreender como se estrutura sua rede urbana, com ênfase para as condições espaciais de ocupação e as diferentes intensidades de conexão estabelecida entre os municípios norte mineiros, ressalta-se que as relações de dependência estabelecida entre eles reforçam demandas/carências de infraestrutura no contexto local. Já a última etapa será direcionada para uma abordagem crítica sobre o processo de planejamento e gestão e suas perspectivas de desenvolvimento a partir das diretrizes locais de ordenamento do solo, de educação e saúde, tendo como

${ }^{1}$ Em relação aos estudos já desenvolvidos sobre Montes Claros, cidade de porte médio, consultar enfoque o estudo comparativo dos planos diretores dos municípios polarizadores na rede urbana norte mineira.

\section{A Mesorregião do Norte de Minas}

A mesorregião do Norte de Minas é composta por 86 municípios, compreendendo uma área territorial de $124007,2 \mathrm{~km} 2$ e 1.574 .501 habitantes, sendo que $70 \%$ residem em área urbana e $30 \%$ em área rural (IBGE, 2010). Tendo por base a Revisão da Divisão Regional do Brasil, de acordo com critérios do IBGE (2017), são definidos novos limites para as Unidades Mesorregionais, nomeadas de Regiões Geográficas Intermediárias, e para as Unidades Microrregionais, classificadas como Regiões Geográficas Imediatas. A partir dessa nova classificação constituem Regiões Geográficas Imediatas no Norte de Minas as regiões de influência de Januária, de Janaúba, de Salinas, de Pirapora, de São Francisco e de Espinosa (Figura 2). Ainda, devido à rede de influência constituída pelos municípios do Norte de Minas, configura-se a Região Geográfica Intermediária de Montes Claros.

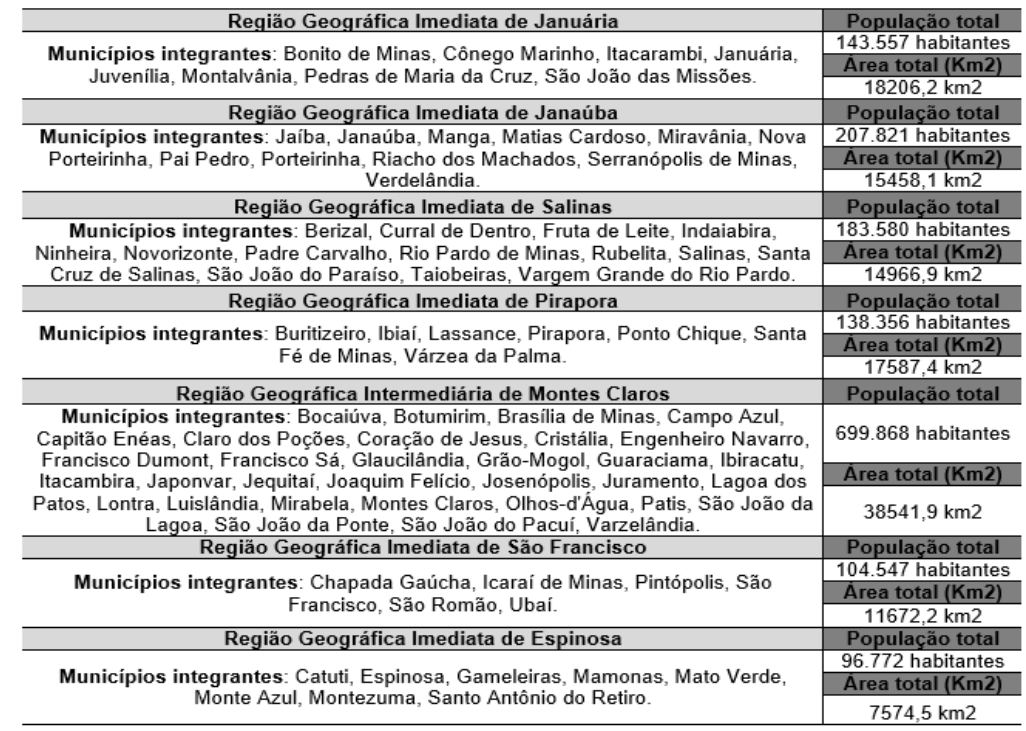

Figura 2: Regiões Geográficas do Norte de Minas. Fonte: Dados IBGE, 2010. Elaborado por Brenda Melo Bernardes, 2018.

as teses de Doutorado em Geografia de Pereira (2007) e França (2012). 
A tabela acima mostra a relação dos municípios integrantes de cada região geográfica, a população total (urbana e rural) e a área territorial equivalente. Nota-se o número expressivo de municípios que integram a Região Geográfica Intermediária de Montes Claros em função do maior grau de influência do município de porte médio, quando comparado às demais regiões geográficas de escala imediata.

Não obstante, sobressaem nessa mesorregião municípios de menor porte com população inferior a 20.000 habitantes - foram contabilizados 66 do total de 86 municípios (IBGE, 2010). Essa situação pode ser considerada um fator relevante de influência no desenvolvimento urbano dos municípios uma vez que, de acordo com critérios do Estatuto da Cidade/2001, extingue a obrigatoriedade de elaboração do Plano Diretor.

Assim, tendo em vista que o plano diretor constitui um importante instrumento para direcionamento do uso dos recursos orçamentários, conforme características específicas de ocupação do solo e demandas de crescimento econômico, a sua ausência dificulta a aplicação de diretrizes locais condizentes com a realidade socioeconômica dos municípios. Além disso, no caso especifico dos municípios que integram a Mesorregião do Norte de Minas, o fato da lei municipal não ser obrigatória para cidades com menos de 20.000 habitantes, que constitui a maior parcela da Mesorregião do Norte de Minas, pode influenciar negativamente no fortalecimento da sua participação na rede urbana, uma vez que as cidades, em sua maioria, carecem de infraestrutura e de estratégias voltadas ao desenvolvimento municipal e regional mais equilibrado e menos excludente.

Ainda sobre as características dessa região geográfica, Pereira (2007) ressalta que o Norte de Minas apresenta singularidades no que tange seus aspectos socioeconômicos. Presencia-se desigualdade socioeconômica, caracterizando paisagens distintas marcadas, de um lado, pela pobreza, seca e marginalização social, sobretudo no âmbito rural e, de outro, pela concentração de renda nas mãos de uma minoria elitizada. Nota-se, nesse sentido, a tendência de priorização de intervenções conduzidas pelo poder público no contexto municipal voltadas aos interesses de uma pequena parcela da sociedade, que exerce maior influência econômica ou política, sobre a condução da política urbana. Assim, nesse cenário os interesses mercadológicos muitas vezes sobrepõem ao coletivo na condução de intervenções públicas e torna-se difícil articular os interesses de segmentos sociais diversos na definição de estratégias de desenvolvimento compatíveis com contextos locais singulares.

Em relação à rede urbana do Norte de Minas, Montes Claros destaca-se como capital regional pela forte concentração de serviços de saúde, pela oferta de ensino superior, como fornecedor de insumos para produtores agropecuários e pela oferta de serviços diversificados (IBGE, 2008). Não obstante, o município, que configura um centro urbano regional de porte médio de influência primária, estabelece uma rede de conexões pelo processo de aglomeração urbana descontínua com os demais municípios do Norte de Minas (FRANÇA, 2012).

Desse modo, tendo em vista essa forte dependência dos municípios de menor porte em relação a Montes Claros, verifica-se a sobrecarga de serviços públicos, especialmente de saúde, na centralidade regional. Leite; Primo (2016) reforçam essa questão de dependência dos municípios norte mineiros do centro regional de Montes Claros ao colocarem que a dificuldade em se obter recursos financeiros para investimento em infraestrutura por parte dos municípios de menor porte, que tem como principal receita a arrecadação do Fundo de Participação dos Municípios (FPM), tem influenciado negativamente na oferta de serviços públicos primordiais. Diante dessa problemática, tem sido frequente a instituição de consórcios públicos intermunicipais como forma de suprir essa alta demanda a partir do processo de gestão integrada.

Nesse sentido, coloca-se a crescente demanda de fortalecimento do processo de gestão integrada dos municípios de menor porte e de sua relação com o contexto regional, sendo primordial a delimitação das escalas de atuação que compete as diferentes esferas - municipal, estadual e federal e de promoção de articulações verticais e horizontais, considerando, inclusive, a possibilidade de instituição de poderes compartilhados conforme interesses comuns, como os consórcios mencionados. Assim, diante das dificuldades enfrentadas pelos municípios no processo de gestão local, as relações intermunicipais têm sido vistas como alternativas para minimizar o impacto proveniente das reduções das receitas orçamentárias (PIRES, 2016). 
Já em relação ao setor educacional, Montes Claros destaca-se pela alta concentração de instituições de ensino superior, o que torna frequente os deslocamentos pendulares realizados por estudantes que residem em municípios de menor porte do Norte de Minas. França e Soares (2007) enfatizam a relevância de Montes Claros no segmento educacional ao colocarem que a oferta de cursos de graduação e de pós-graduação tem contribuído para impulsionar não só a qualificação profissional da região, mas também o desenvolvimento econômico do município, por meio, sobretudo, da instalação de atividades do setor terciário. Além disso, a importância de Montes Claros como centralidade, tem contribuído para a conformação de uma rede de influência urbana que transcende os limites do Norte de Minas, agregando as regiões noroeste e leste do Estado e o sul da Bahia (FRANÇA; SOARES, 2007).

Vale destacar, nesse contexto, que a ocupação esparsa dessa mesorregião faz com que predominem redes longas de conexão entre os municípios (IBGE, 2008) que dependem, em sua maioria, diretamente de Montes Claros para acesso à serviços especializados, sobretudo nos setores de educação e saúde. Tal situação evidencia a necessidade de promover a descentralização da rede urbana norte mineira por meio do fortalecimento de outros municípios, para desempenharem a função de centros urbanos.

Desse modo, a importância de Montes Claros como centro regional, sobretudo pela oferta de serviços de saúde, educação e comércio diversificados, associado a alta demanda por bens e serviços, evidenciam o processo de integração da rede urbana com os centros emergentes, que desempenham o papel de centros urbanos secundários, e os municípios de menor porte do Norte de Minas.

Ademais, em municípios de menor porte, constata-se, além da maior dependência em relação ao acesso a bens e serviços de municípios de maior porte, que constituem centralidades na rede urbana norte-mineira, a prática de importação de modelos padronizados de leis, como o Plano Diretor, sendo recorrente, inclusive, a apropriação de planos de municípios de maior porte populacional sem a devida adequação à escala local. Tal situação confirma entraves para a aplicabilidade dos instrumentos correlacionados no plano devido à insuficiência de análise específica das demandas de cada localidade.

Nesse contexto, verifica-se como problemas atrelados à elaboração e aplicabilidade do plano diretor: a carência de corpo técnico capacitado para inclusão de políticas interinstitucionais, que poderiam contribuir para angariar recursos para o desenvolvimento urbano; o incipiente conhecimento quanto aos mecanismos instituídos pelo Estatuto da Cidade, o que leva a interpretações equivocadas quanto à possibilidade de aplicação adequada à realidade do município; a priorização de investimentos direcionados as demandas básicas de educação e saúde, em detrimento à outros setores também carentes de melhorias; pouco interesse político no processo de planejamento; tendências de homogeneização nas questões relativas ao uso e ordenamento do solo, sem considerar as particularidades de cada área, entre outras questões (BERNARDY, 2013).

Assim, ganha destaque as limitações na transposição da teoria para a prática dos princípios expressos nos planos diretores de modo geral, Vainer (2002) ainda enfatiza, nesse sentido, os entraves da capacidade de atuação das gestões municipais, tendo em vista a limitação de raio de abrangência com que o poder público muitas vezes tem que lidar na definição das políticas urbanas, sem uma articulação urbana multiescalar.

Ademais, no Norte de Minas está situação é agravada diante das condições da sua rede urbana concentrada no centro principal, isto é, em Montes Claros, o que torna difícil a articulação de políticas urbanas que possam contribuir para o fortalecimento de outros centros urbanos, apesar de se verificar tendência de ramificações por meio da formação de centros emergentes que ofertam serviços locais demandados por municípios menores situados em seu entorno. Ainda, verifica-se um número reduzido de municípios que concentram indústrias, serviços e atividades econômicas mais expressivas, exercendo o papel de polarizadores em nível regional.

Por isso, torna-se fundamental entender o papel das cidades emergentes na rede urbana regional e sua capacidade de gestão dos problemas decorrentes da sua centralidade na rede urbana. Nesse contexto, o plano diretor se destaca como um indicador preliminar para demostrar as competências e entraves no exercício da gestão do território municipal, visando o desenvolvimento municipal e regional.

Diante dessas constatações é necessário destacar que há uma macrocefalia na rede urbana do Norte de Minas, sendo Montes Claros um centro altamente demando para oferta de serviços à população regional. Essa situação afeta a qualidade dos serviços ofertados nessa cidade, pois converge para ela uma população superior a capacidade de atendimento dos serviços disponíveis, notadamente 
saúde e educação. Portanto, a estruturação de serviços públicos em outras cidades da rede urbana norte mineira irá descentralizar o intenso e único fluxo para Montes Claros. Nesse sentido, que os instrumentos de ordenamento territorial e definição de políticas públicas, como o Plano Diretor, são imprescindíveis para identificar e planejar as ações para criar essa infraestrutura e diversificar essa oferta de serviços.

\section{O plano diretor como instrumento de gestão local dos Centros Emergen- tes no Norte de Minas}

Sobre a utilização do Plano Diretor como instrumento de planejamento e gestão, Villaça (2005) destaca que um dos principais equívocos relacionados com a sua aplicabilidade consiste na atribuição de importância exacerbada ao plano, que é visto como solução para os problemas urbanos, ignorando, muitas vezes, o enorme abismo existe entre o discurso e a prática. Nesse sentido, os Planos Diretores podem resultar em discursos tecnocráticos que não contribuem efetivamente para o desenvolvimento das cidades por não articular características específicas de cada localidade na sua elaboração (VILLAÇA, 2005).

De tal modo, é recorrente nas cidades que dispõe da lei municipal discrepante desigualdade de acesso a renda e à infraestrutura básica, que são problemas crônicos em centros urbanos mas que não são combatidos pelo Plano Diretor; sua utilização preponderante para atendimento de interesses mercadológicos, que beneficiam uma parte da sociedade de maior poder econômico, associado a falta de incorporação da participação popular e da transparência na condução dos projetos urbanos (VILLAÇA, 2005).

Assim, diante dos desafios que caracterizam o processo de elaboração do Plano Diretor, torna-se importante compreender as características peculiares do Norte de Minas e dos municípios que a compõem selecionados para estudo para fundamentar análise crítica sobre o processo de planejamento e gestão local.

Tratando especificamente da influência dos planos diretores no desenvolvimento local dos municípios situados no Norte de Minas, foram definidos como objetos de estudo sete municípios que se classificam como centros emergentes e que desempenham papel secundário na conformação da rede urbana norte-mineira, a saber: Bocaiúva, Espinosa, Janaúba, Januária, Pirapora, Salinas e São Francisco. Esses municípios, que possuem população total superior à 30.000 habitantes e inferior à
70.000 habitantes (IBGE, 2010), desempenham o papel de centralidades nas regiões imediatas especificadas.

O critério de seleção considerado foi de eleger um município representante de cada região geográfica (imediata e intermediária), tendo como fator de escolha o tamanho populacional e sua maior influência na formação da rede urbana no Norte de Minas. Dessa forma, foram selecionados os municípios com maior tamanho populacional de cada região imediata e, no caso da Região Intermediária de Montes Claros, foi selecionado o município de Bocaiúva, já que é o que apresenta maior tamanho populacional - no caso, Montes Claros não foi escolhida como representante porque configura um centro de importância primária no Norte de Minas e é classificada como cidade de porte médio. O mapa abaixo evidencia a localização geográfica de cada um dos municípios selecionados e sua posição em relação ao centro regional de Montes Claros (Figura 3).

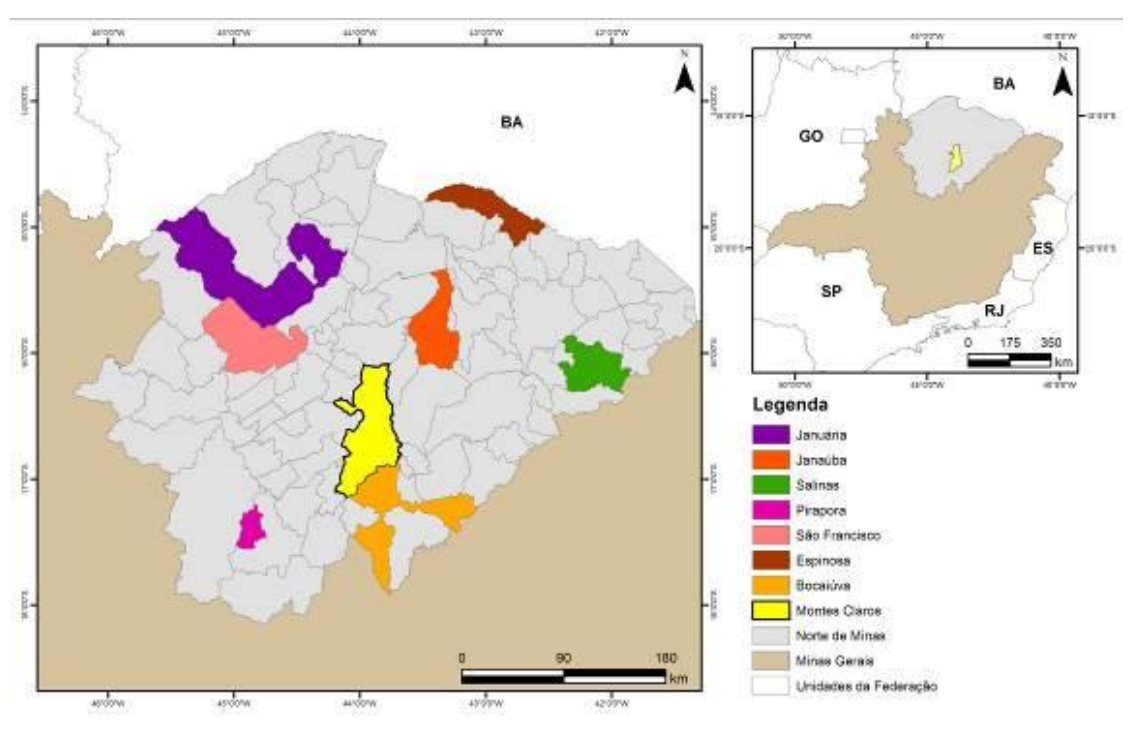

Figura 3: Municípios selecionados para estudo que compõem a Mesorregião do Norte de Minas. Fonte: Base Cartográfica IBGE, 2010. Elaborado por Brenda Melo Bernardes, 2018. 
Sobre o processo de desenvolvimento dos municípios no Norte de Minas, de modo geral, pode-se dizer que foi impulsionado, dentre outros fatores, pela instalação da Estrada de Ferro Central do Brasil na década de 1920 e pelos incentivos fiscais da Superintendência de Desenvolvimento do Nordeste (SUDENE), que estimularam o desenvolvimento industrial a partir da década de 1960, sobretudo da sede Montes Claros. Desse modo, esses marcos históricos influenciaram no processo de urbanização do Norte de Minas (FRANÇA, 2012).

Ainda em relação aos municípios selecionados para estudo, é importante destacar, no que tange aos princípios de ordenamento do solo, que pelo fato de todos eles apresentam população superior a 20.000 habitantes, torna obrigatório a elaboração do Plano Diretor. Contudo, apesar das exigências, o município de Espinosa, que apresenta população total de 31.113 habitantes - conforme dados do último censo do IBGE (2010), não dispõe de Plano Diretor. O município apresenta outras leis municipais de ordenamento do solo como Lei Orgânica e de Parcelamento do Solo.

Assim, a ausência do Plano Diretor em Espinosa como recurso de planejamento e gestão urbana evidenciam uma situação recorrente no Norte de Minas. Além disso, destaca-se a necessidade de maior compromisso dos gestores locais em instituir diretrizes específicas de desenvolvimento, por meio das leis municipais, tendo em vista as demandas de descentralização diante da sobrecarga da rede urbana e de facilidade de acesso aos serviços básicos e especializados por municípios que apresentam potencial para conformação de centralidades.

Em relação aos planos diretores dos municípios selecionados, destaca-se que o foco da abordagem é mais direcionada a aplicabilidade no Plano Diretor dos princípios expressos pelo Estatuto da Cidade - Lei Federal 10.257/01 (BRASIL, 2001), considerando, respectivamente, os instrumentos que tratam do combate à retenção especulativa de terras, da regularização fundiária e de diretrizes que se vinculam aos princípios de gestão democrática das cidades, inclusão social e equilíbrio ambiental.

A partir da análise comparativa dos planos diretores selecionados para estudo, de modo geral, é possível inferir que eles abordam, ainda que de forma incipiente, sobre políticas de integração regional, ambiental, cultural, de educação, de saúde, de desenvolvimento econômico e de infraestrutura urbana e serviços públicos. Além disso, relacionam os instrumentos de política urbana do Estatuto da Cidade, apesar de carecerem de maior aprofundamento sobre sua aplicabilidade conforme realidade local.

É importante mencionar que nos Planos Diretores de Bocaiúva (Projeto de lei complementar no 38/2006), de Pirapora (Lei oํ 1846/2006), de Salinas (Lei Complemen$\operatorname{tar} n^{\circ}$ 008/2006) e de São Francisco (Lei no 2186/2004) constata-se a reprodução da estrutura hierárquica - equivalente à divisão e nomeação dos títulos, capítulos e seções, bem como, das diretrizes legais de modo geral, sem elencar especificidades dos municípios. Verifica-se, em relação aos Planos Diretores de Bocaiúva e de Pirapora, apenas alterações pontuais em algumas seções - constatado principalmente nos capítulos que tratam das diretrizes de desenvolvimento urbano, do Macrozoneamento e dos Instrumentos de Política urbana, mas que não contribuem para a distinção efetiva entre os conteúdos dos planos diretores em questão. Essa situação revela uma característica recorrente, sobretudo em municípios de pequeno porte, de importação de textos legais de outros planos diretores, o que faz com que o instrumento tenha limitações de aplicabilidade no contexto municipal devido à ausência ou escassez de diretrizes específicas que orientem o desenvolvimento local.

Em relação às políticas de integração regional, a partir da análise do plano diretor de Janaúba (Lei oㅜ 1.744/2007 com suas respectivas revisões Lei no 2.104/2015 e Lei oํ 2.269/2018), é mencionada a necessidade de integração entre os municípios do Norte de Minas no que tange questões ambientais, econômicas, de infraestrutura e serviços essenciais. Apesar da relevância desse item, ele é pouco aprofundado em relação às possibilidades de integração de políticas sociais, das ações de mobilidade, de melhoria de articulações viárias e de integração econômica. Já nos Planos Diretores de Bocaiúva (Projeto de lei complementar no 38/2006), de Januária (Lei Complementar no 068/2008), de Pirapora (Lei no 1846/2006), de Salinas (Lei Complementar no 008/2006) e de São Francisco (Lei no 2186/2004) essa questão é tratada ainda de modo mais superficial, sem elencar diretrizes primordiais para promover as relações intermunicipais. 
Nesse sentido, o fortalecimento das políticas públicas regionais possibilitaria a maior repartição de recursos financeiros para investimento em municípios que carecem de infraestrutura básica ou que apresentam potencial para abrigar infraestrutura especializada, de acordo com suas características particulares, contribuindo para maior estruturação do potencial econômico, de lazer ou ambiental em âmbito regional.

Sobre a política ambiental, tanto o Plano Diretor de Janaúba quanto o de Januária definem diretrizes para instituição das áreas de interesse de proteção ambiental e para as áreas que apresentam fragilidades ambientais ou que constituem áreas de risco à ocupação. A legislação de Janaúba apresenta uma análise mais minuciosa sobre esse aspecto ao especificar medidas de proteção e de manutenção de áreas de preservação permanente e das Unidades de Conservação.

Ainda em relação à política ambiental, observa-se a partir da análise dos Planos Diretores de Pirapora, de Salinas e de São Francisco a importância atribuída ao Rio São Francisco e aos Rios Salinas, Bananal e Ribeirão no processo de desenvolvimento local dos municípios. Ademais, a partir dos Planos Diretores analisados é evidenciado o interesse de constituição de um plano de ação voltado para a o processo de recuperação e preservação dos rios, para estímulo de práticas culturais em sua orla e para maior participação social no processo de gestão.

No que tange às políticas de inclusão social, em análise comparativa com o Plano Diretor de Janaúba, a legislação de Januária carece de aprofundamento de diretrizes em relação às áreas rurais, considerando que o município é constituído, de acordo com os dados do IBGE (2010), por 42\% da população residente em áreas rurais. Observa-se essa mesma situação quando analisado o Plano Diretor de Bocaiúva (população rural de 22\%), o Plano Diretor de Pirapora, o que pode, nesse caso, ser justificado pela população inexpressiva que reside em áreas rurais (2\%), o Plano Diretor de Salinas (população rural de 22\%) e o Plano Diretor de São Francisco (população rural de 37\%). Já no município de Janaúba, apesar da porcentagem menor de população que reside em áreas rurais (35\%), quando comparado à Januária, são mencionadas estratégias para implantação de programas específicos que visam à promoção de saúde, educação, infraestrutura, mobilidade e lazer e o incentivo à vitalidade econômica desses locais.
Considerando especificamente os instrumentos de política urbana regulamentados pelo Estatuto da Cidade, os Planos Diretores dos municípios analisados relacionam os mecanismos jurídicos que regulamentam a questão urbana como: Cessão do direito de superfície, Outorga onerosa do direito de construir ou solo criado, Direito de preempção, Operações urbanas consorciadas, Do parcelamento, edificação ou utilização compulsória, Do IPTU progressivo no tempo, Da desapropriação com pagamento em títulos, Transferência do direito de construir, Concessão de direito real de uso e regularização fundiária. Entretanto, nota-se que é recorrente a reprodução dos princípios vinculados ao Estatuto da Cidade sem se atentar para as particularidades da política de desenvolvimento urbano local.

Apesar de mencionados os instrumentos de política urbana, Saboya (2007) reforça que a efetividade da sua aplicação é garantida quando os instrumentos são atrelados aos dados cadastrais dos municípios, de modo que os registros documentais relativos à posse dos imóveis poderão contribuir para a obtenção mais precisa de informações sobre controle de ordenamento do solo e de áreas que carecem de regularização fundiária, sendo considerados dados primordiais para aplicabilidade dos instrumentos do Estatuto condizentes com a realidade local.

Nesse sentido, no caso do Plano Diretor de Janaúba, é recorrente a definição de todo o perímetro urbano como passível de aplicação dos instrumentos de tributários e de controle de uso do solo, o que dificulta sua efetividade considerando as particularidades de cada área que integram o município. Já nos planos de Januária, de Pirapora e de Salinas, em relação ao parcelamento, edificação e utilização compulsório, são relacionados os critérios de metragem e potencial construtivo passíveis de aplicação do instrumento quando se trata de terrenos subutilizados e não edificados, tais critérios carecem no plano de Janaúba. Ademais, o Plano Diretor de Bocaiúva mostra-se mais completo sobre esse aspecto ao relacionar as zonas em que poderão ser aplicados os instrumentos mencionados.

Em relação aos instrumentos de IPTU Progressivo no Tempo e desapropriação com pagamentos de títulos da dívida pública, em todos os planos diretores analisados são especificados os prazos para aplicabilidade do instrumento e alguns critérios na definição da alíquota do IPTU Progressivo. Ainda, nos municípios em análise o instrumento de operação urbana é tratado de forma genérica. Não obstante, Bocaiúva é o único município dos selecionados para estudo que apresenta diretrizes 
incipientes sobre a definição das áreas passíveis de aplicação do instrumento de operação urbana por meio do zoneamento.

Sobre a possibilidade de utilização do instrumento da outorga onerosa do direito de construir e da transferência do direito de construir, o Plano Diretor de Januária mostra-se mais reducionista quando comparado aos planos de Bocaiúva e de Janaúba, já que não há especificação das áreas passíveis de aplicação do instrumento de outorga. Esse instrumento pressupõe a definição de critérios de zoneamento, a destinação da contrapartida arrecadada por meio da venda de potencial construtivo, a especificação de quais são os setores carentes de infraestrutura urbana que poderão se beneficiar com investimentos. Nos demais municípios em estudo não são relacionados nos Planos Diretores a possibilidade de aplicação da outorga.

Já em relação ao instrumento transferência do direito de construir, o Plano Diretor de Januária apresenta abordagem mais genérica quando comparado aos demais, já que não são especificados os critérios legais e de registro em cartório que conferem aplicabilidade ao instrumento.

Sobre a regularização fundiária, em todos os planos diretores analisados a problemática é tratada de modo superficial, sem clareza quanto às diretrizes e prioridades dos municípios. Os planos necessitam de aprofundamento quanto às especificações de destinação de fundo de habitação de interesse social, da constituição de ZEIS e dos possíveis instrumentos de ordenamento jurídico que poderão ser atrelados ao processo de regularização.

Por fim, um dos principais eixos previstos pelo Estatuto da Cidade corresponde à gestão democrática das cidades (BRASIL, Lei 10.257/2001, cap. IV). Para que o instrumento seja utilizado de modo efetivo, são definidos como mecanismos de participação pelo Estatuto, além do processo eleitoral, a instituição de instâncias participativas no processo de planejamento e gestão e a exigência de transparência do poder público perante a sociedade no que tange a tomada de decisões e aplicabilidade dos recursos públicos.

Em relação ao processo de gestão democrática, constata-se que, de modo geral, os municípios em análise elencam mecanismos para incorporação da participação popular. Entretanto, as diretrizes apresentadas na maioria dos planos, apesar de evidenciarem a necessidade de se incorporar instâncias participativas como a realização de audiências públicas e a instituição do Conselho Municipal de Política Urbana, são genéricas, já que reproduzem os princípios colocados pelo Estatuto da Cidade sem adequação às demandas municipais. Todavia, a maior parte dos municípios analisados - Bocaiúva, Pirapora, de Salinas e de São Francisco, enfatizam em seus planos a composição de representantes dos diversos setores da sociedade civil e do poder executivo, bem como, as atribuições do conselho. Avritzer (2008) trata da importância do processo de gestão democrática ao colocar que o fato dos conselhos adotarem o modelo paritário minimiza a capacidade de manipulação do instrumento para atendimento dos interesses de uma minoria, tendo em vista o poder atribuído à sociedade civil na aplicação de sanções em casos de violação da participação popular na aprovação das ações do poder público.

Sobre as políticas de saúde, o município de Janaúba, quando comparado aos demais analisados, apresenta diretrizes mais específicas, em conformidade com as normas do Sistema Único de Saúde, voltadas para o interesse de instituição do processo de descentralização de oferta dos serviços por meio de políticas sociais voltadas para áreas rurais e na definição da hierarquia de atendimentos, conforme complexidade dos procedimentos envolvidos para maior qualidade dos serviços prestados. Nos demais municípios são apresentadas diretrizes básicas para melhoria das condições de atendimento, instituição de programas de saúde e de equipamentos, conforme demandas constatadas no município.

Apesar das diretrizes elencadas de modo geral nos planos diretores analisados relativos às políticas de saúde, ao estabelecer uma análise comparativa do número de estabelecimentos de saúde distribuídos nos municípios selecionados para estudo, verifica-se a discrepância quando comparado à maior concentração no polo regional de Montes Claros (Figura 4).

Enquanto no centro regional contatam-se 116 estabelecimentos de saúde do SUS (IBGE, 2009), nos demais municípios analisados os equipamentos públicos implantados compreendem a faixa do número mínimo de 13 estabelecimentos, identificado em Espinosa, ao número máximo de 37, verificado em Pirapora. 


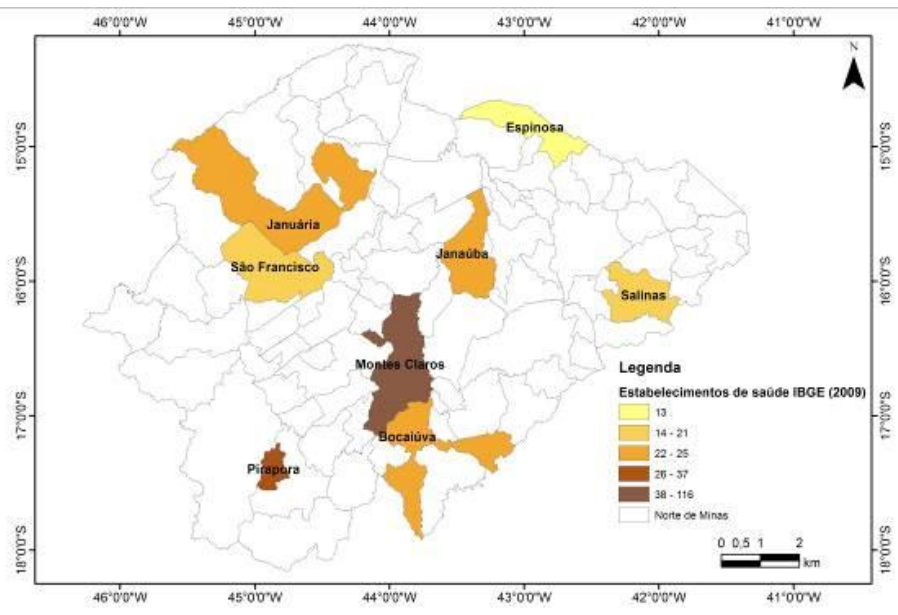

Figura 4: Estabelecimentos de saúde situados nos municípios em estudo. Fonte: Base Cartográfica IBGE, 2009. Elaborado por Brenda Melo Bernardes, 2018.

Essa constatação evidencia a forte dependência dos municípios de menor porte com a centralidade, sobretudo em relação à oferta de serviços de saúde mais especializados, o que torna necessário a realização de deslocamentos da população proveniente dos municípios de menor porte do Norte de Minas para ter acesso aos serviços que exigem maior complexidade de atendimento em hospitais e clinicas.

Já sobre a política municipal de educação, destaca-se em todos os planos diretores analisados o interesse na instituição de um sistema de educação integral, de capacitação profissional e na melhoria da oferta e qualidade de ensino nos níveis de educação infantil e fundamental. Contudo, apesar dessas diretrizes, verifica-se um número inexpressivo de instituições de educação nos municípios de menor porte do Norte de Minas quando comparado à Montes Claros. Enquanto na capital regional encontram-se implantadas 148 escolas de ensino fundamental (Figura 5) e 52 escolas de ensino médio, nos demais municípios analisados, o número máximo de escolas constatadas foi no município de Januária, sendo 75 de ensino fundamental e 18 de ensino médio. Ainda, pelo fato da política de educação ser direcionada para os níveis de educação infantil e fundamental, evidencia-se novamente a dependência em relação aos serviços oferecidos em Montes Claros, sobretudo no que tange a oferta de ensino superior e profissionalizante.
No ensino superior ganham evidencia o campus da Universidade Federal de Minas Gerais (UFMG), o Instituto Federal do Norte de Minas Gerais (IFNMG) e a Universidade Estadual de Montes Claros (UNIMONTES). Além de dois centros universitários e diversas faculdades privadas. Assim, a instituição do polo universitário tem impulsionado o desenvolvimento do centro regional e a realização dos movimentos pendulares por parte de alunos que residem em municípios vizinhos.

Deste modo, tendo como base a análise apresentada sobre os planos diretores dos municípios selecionados para estudo do Norte de Minas e ressaltada à ocorrência de importação das diretrizes de outros planos, sem o embasamento nas características e demandas específicas locais, pode-se inferir que essa situação poderá afetar negativamente o processo de desenvolvimento urbano da mesorregião. Essa constatação é evidenciada já que os possíveis mecanismos que poderiam contribuir para o ordenamento e diversidade de usos do solo, para efetivar os processos de regularização fundiária, de justiça social e de equilíbrio ambiental, são tratados de modo genérico. Ainda, nota-se que as políticas de ordenamento do solo, saúde e educação, especificados nos Planos Diretores dos municípios analisados, apresentam distanciamento quanto à sua aplicabilidade no contexto local e revelam forte dependência sobre a oferta de serviços concentrada no centro regional de Montes Claros. Tal situação evidencia uma rede urbana desequilibrada, tendo destaque problemas como a sobrecarga de serviços públicos, segregação socioespacial, desigualdade econômica e distribuição desigual de investimentos públicos.

Ademais, em relação aos desafios vinculados à aplicabilidade do Plano Diretor como instrumento de planejamento e gestão, tendo como foco de estudo os centros emergentes do Norte de Minas, verifica-se, entre outras questões, à necessidade de adequação da lei municipal à realidade local; à dificuldade de se obter efetivamente maior autonomia no processo de gestão, sobretudo no que tange os municípios de menor porte que necessitam de articular um processo de gestão integrada no contexto regional para obter recursos financeiros proveniente das instâncias estadual e federal e, consequentemente, o desafio de se alcançar essa articulação urbana multiescalar para eficiência no direcionamento de políticas públicas. 


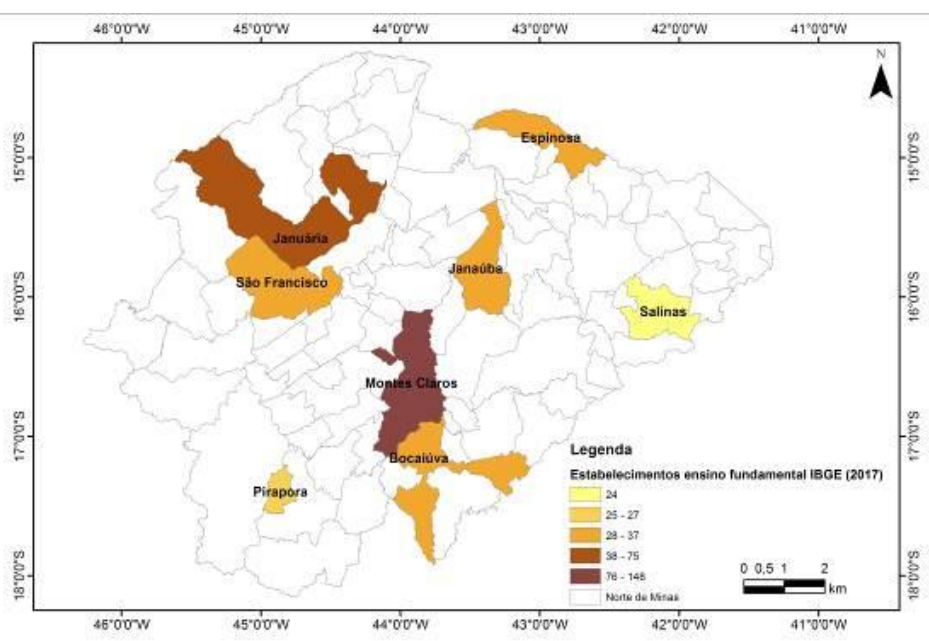

Figura 5: Estabelecimentos de ensino fundamental situados nos municípios em estudo. Fonte: Base Cartográfica IBGE, 2017. Elaborado por Brenda Melo Bernardes, 2018.

Com essas análises constata-se uma necessidade de adequação do plano diretor a realidade do município e sua posição na rede urbana regional. Essa discrepância do que consta no plano e a realidade é explicada, entre outros fatores, pelo fato de, muitas vezes, se elaborar o plano diretor apenas para tender a exigência legal, pois são textos com diretrizes vagas e desconexas da realidade. Dessa maneira, o plano diretor deveria trazer o diagnóstico do município, orientando os setores carentes de investimentos e as estratégias para integração da sua infraestrutura e serviços na rede regional.

Logo, um plano de desenvolvimento regional, com a participação de todos munícipios, é necessário, uma vez que os problemas vivenciados pelo município não estão circunscritos ao seu território, pois o fluxo das demandas e das ofertas transcendem os limites municipais. O desenvolvimento urbano dos municípios associado à gestão integrada de recursos, por meio do processo de cooperação interinstitucional ou até mesmo de instituição de regiões metropolitanas, muitas vezes são vistos como alternativas para captação de recursos financeiros e para minimizar as condições alarmantes de desigualdade econômica e de segregação socioespacial.

\section{Considerações finais}

Diante do objetivo deste trabalho de compreender a influência que os princípios de ordenamento do solo, bem como, as políticas de educação e saúde exercem no desenvolvimento dos municípios de pequeno porte do Norte de Minas, é possível inferir que apesar do Plano Diretor exercer papel fundamental na conciliação das estratégias de planejamento e gestão que irão orientar o desenvolvimento municipal, verifica-se fragilidades quanto à sua implantação no Norte de Minas, o que dificulta não só a tomada de decisões condizentes com a realidade local, como também o processo de gestão integrada no contexto regional. Assim, no Norte de Minas presenciam-se tanto situações de municípios que carecem de legislação municipal de ordenamento do solo, como é o caso de Espinosa, quanto também a importação de diretrizes legais de outros planos diretores sem adequação à realidade local, situação constatada nos municípios de Bocaiúva, Pirapora, Salinas e São Francisco.

No contexto regional, os planos diretores, de modo geral, mostram-se reducionistas e insuficientes quanto à especificação de estratégias de políticas públicas integradas. É importante mencionar que, em função da ocupação espraiada no Norte de Minas, Montes Claros e os municípios adjacentes não se integram pelo processo de conurbação. Essa situação é evidenciada pelas redes de longa distância que prejudicam a articulação da capital regional com outros centros urbanos (IBGE, 2008). Mesmo com essa peculiaridade quanto à estrutura física-territorial, a intensa desigualdade socioeconômica que assola o Norte de Minas evidencia a necessidade emergente de se intensificar as relações intermunicipais para impulsionar o desenvolvimento dos municípios que integram essa mesorregião.

No que tange às políticas de educação e saúde, verifica-se a partir da análise dos planos diretores dos municípios de pequeno porte, de modo geral, diretrizes voltadas à oferta e melhoria de atendimento dos serviços básicos de saúde e, no setor educacional, o interesse de melhoria do ensino infantil e fundamental. Contudo, verifica-se que além dos municípios apresentarem poucos estabelecimentos de saúde e educação, quando comparado à maior oferta desses equipamentos na cidade de porte médio Montes Claros (IBGE, 2010), carecem de serviços de saúde especializados e de instituições de ensino técnico e superior. Desse modo, não se pode afirmar que os princípios expressos nos Planos Diretores para esses setores têm sido efetivamente colocados em prática por meio de políticas públicas. Ainda, a 
maior dependência dos municípios de pequeno porte de recursos orçamentários provenientes de entes estatais e federais dificultam mudanças estruturais na oferta e qualidade dos estabelecimentos de saúde e educação. Ademais, essa situação reforça a dependência desses municípios em relação a Montes Claros e sobrecarrega a infraestrutura do centro regional, ocasionando problemas diversos relativos à alta demanda de profissionais especializados e de equipamentos de saúde e educação, de mobilidade e de carência de infraestrutura para acolhimento da população proveniente de outros municípios.

Em relação ao processo de gestão democrática e aos instrumentos de política urbana previstos no Estatuto da Cidade/2001, verifica-se que, de modo geral, ocorre a reprodução dos princípios nos Planos Diretores sem o cuidado de se adequar essas diretrizes à escala do município e as demandas presenciadas no contexto local. Dessa forma, torna-se novamente restringida a capacidade de gestão do poder público pela carência de um estudo aprofundado que permita compreender as limitações e perspectivas de desenvolvimento dos municípios.

Portanto, essas situações constatadas elucidam, entre outras questões, a necessidade de se incorporar efetivamente a participação da sociedade civil no processo de planejamento e gestão para atendimento das demandas sociais e urbanas inerentes aos municípios e de se ter um corpo técnico capacitado para a elaboração dos planos, evitando sua terceirização que possa comprometer sua qualidade e legitimação. Além disso, é fundamental o compromisso dos gestores locais na elaboração de planos que não resultem somente em modelos padronizados que serão posteriormente engavetados, mas que de fato contribuam para minimizar a desigualdade social, para fazer cumprir a função social da cidade e para melhorar as condições de vida nos municípios, tanto no meio urbano quanto rural.

Ademais, considera-se fundamental no Norte de Minas que os planos municipais priorizem as relações intermunicipais, com o intuito de contribuir para o fortalecimento da capacidade de atuação dos gestores públicos e para a implementação das políticas públicas nos municípios, sobretudo os que apresentam mais carências, como de pequeno porte.

\section{Referências}

AMORIM FILHO, Oswaldo Bueno; RIGOTTI, José Irineu Rangel; CAMPOS, Jarvis. Os níveis hierárquicos das cidades médias de Minas Gerais. RA'E GA, Curitiba, n.13, p.7-18, 2007.

AVRITZER, Leonardo. Instituições participativas e desenho institucional: algumas considerações sobre a variação da participação no Brasil democrático. Opinião Pública, Campinas, v. 14, n. 1, p. 43-64, Jun. 2008.

BERNARDY, Rógis Juarez. O Planejamento Urbano de pequenos Municípios com base no Plano Diretor. Desenvolvimento em Questão, ljuí, n.22, p.4-34, ano 11, n. 22, jan./abr. 2013.

BOCAIÚVA, Prefeitura Municipal. Projeto de Lei Complementar ㄲo 38 de 2006. Dispõe sobre Plano Diretor Estratégico, o sistema e o processo de planejamento e gestão do desenvolvimento o Município de Bocaiúva Estado de Minas Gerais. Bocaiúva, Câmara Municipal, 2006, s/p.

BRASIL. Lei no 10.257 de 10 de julho de 2001. Regulamenta os artigos 182 e 183 da Constituição Federal, estabelece diretrizes da política urbana e dá outras providências. Brasília, Câmara dos deputados, 2001, 17 p. Disponível em: <http://www2.camara.leg.br/legin/fed/lei/2001/lei-10257-10-julho-2001-327901-normaatualizada-pl.pdf>. Acesso em: 09 out. 2019.

CASTRO, Alexandre. Novas Divisões Regionais do Brasil: Regiões Geográficas Imediatas e Regiões Geográficas Intermediárias. Rede urbana, 2017. Disponível em: <https://aredeurbana.wordpress.com/2017/10/02/novas-divisoes-regionais-dobrasil-regioes-geograficas-imediatas-e-regioes-geograficas-intermediarias/>. Acesso em: 23 jun. 2020.

FRANÇA, lara Soares de. Aglomeração Urbana Descontínua de Montes Claros/MG: novas configurações socioespaciais. 2012. 399f. Tese (Doutorado em Geografia) - Programa de PósGraduação em Geografia da Universidade Federal de Uberlândia, Uberlândia, 2012. Disponível em: <https://repositorio.ufu.br/handle/123456789/15946>. Acesso em: 09 out. 2019. 
FRANÇA, lara Soares de; SOARES, Beatriz Ribeiro. Expansão urbana em cidades médias: uma reflexão a partir do núcleo e da área central de Montes Claros no Norte de Minas Gerais. Geo UERJ, Rio de Janeiro, v. 2, n. 17, p.47-63, 2 sem. 2007.

INSTITUTO BRASILEIRO DE GEOGRAFIA E ESTATíSTICA [IBGE]. Divisão regional do Brasil em regiões geográficas imediatas e regiões geográficas intermediárias. Rio de Janeiro: IBGE, 2017. 82p.

INSTITUTO BRASILEIRO DE GEOGRAFIA E ESTATÍSTICA [IBGE]. IBGE Cidades. 2009. Disponível em: < https://cidades.ibge.gov.br/>. Acesso em: Acesso em: 09 out. 2019.

INSTITUTO BRASILEIRO DE GEOGRAFIA E ESTATístiCA [IBGE]. Perfil dos municípios brasileiros. Rio de Janeiro, IBGE, 2016. 61p. Disponível em: $<$ https://biblioteca.ibge.gov.br/visualizacao/livros/liv95942.pdf>. Acesso em: 09 out. 2019.

INSTITUTO BRASILEIRO DE GEOGRAFIA E ESTATÍSTICA [IBGE]. Regiões de influência das cidades - 2007. Rio de Janeiro: IBGE, 2008. 201p. Disponível em: <http://www.mma.gov.br/estruturas/PZEE/_arquivos/regic_28.pdf>. Acesso em: 09 out. 2019.

INSTITUTO BRASILEIRO DE GEOGRAFIA E ESTATÍSTICA [IBGE]. Sinopse do Censo Demográfico 2010. Rio de Janeiro: IBGE, 2010. Disponível em: <https://censo2010.ibge.gov.br/sinopse/index.php>. Acesso em: 09 out. 2019.

JANAÚBA, Prefeitura Municipal. Lei no 1.744 de 06 de dezembro de 2007. Dispõe sobre a política de desenvolvimento e de expansão urbana do município de janaúba, institui o plano diretor democrático de desenvolvimento sustentável e dá outras providências. Janaúba, Câmara Municipal, 2007, 181 p.

JANUÁRIA, Prefeitura Municipal. Lei Complementar no 068 de 18 de abril 2008. Dispõe sobre a instituição do Plano Diretor do Município de Januária e dá outras providências. Januária, Câmara Municipal, 2008, 42 p.

LEITE, Marcos Esdras; PRIMO, Núbia Karina Miranda. Os Consórcios Públicos Intermunicipais do Norte de Minas no enfrentamento dos desafios da gestão municipal. In: V Congresso em Desenvolvimento Social, 2016, Montes Claros. Anais...Montes Claros: Unimontes, ANO, p. 5-17.
MONTES CLAROS, Prefeitura de. Cidade para se investir. 2012. Disponível em: $<$ http://www.montesclaros.mg.gov.br/desenvolvimento\%20economico/div_tur/downloads/catalogo.pdf>. Acesso em: 09 out. 2019.

PEREIRA, Anete Marília. Cidade média e região: o significado de Montes Claros no Norte de Minas Gerais. 2007. 351f. Tese (Doutorado em Geografia) - Programa de Pós Graduação em Geografia da Universidade Federal de Uberlândia, Uberlândia, 2007. Disponível em: <http://www.ppgeo.ig.ufu.br/sites/ppgeo.ig.ufu.br/files/Anexos/Bookpage/Anexos_AnetePereira.pdf>. Acesso em: 09 out. 2019.

PEREIRA, Claudinei da Silva; HESPANHOL, Antonio Nivaldo. Região e regionalizações no Estado de Minas Gerais e suas vinculações com as políticas públicas. Revista Formação, n.22, volume 1, 2015, p. 42-70.

PIRAPORA, Prefeitura Municipal. Lei municipal № 1.846 de 2006. Dispõe sobre Plano Diretor Estratégico, o sistema e o processo de planejamento e gestão do desenvolvimento urbano do município de Pirapora. Pirapora, Câmara Municipal, 2006, $58 \mathrm{p}$.

PIRES, Valdemir. Municipalismo no Brasil: origens, avanços pós-1988 e desafios atuais. Cadernos Adenauer XVII. Rio de Janeiro: Fundação Konrad Adenauer, n. 3, p.125-146, 2016.

SABOYA, Renato Tibiriça de. Concepção de uma estrutura de sistema de suporte à elaboração de planos diretores participativos. 2007. 231f. Tese (Doutorado em Engenharia Civil) - Programa de Pós-Graduação em Engenharia Civil da Universidade Federal de Santa Catarina, Florianópolis, 2007. Disponível em: <https://repositorio.ufsc.br/handle/123456789/90032>. Acesso em: 09 out. 2019.

SALINAS, Prefeitura Municipal. Lei Complementar no 008 de 09 de Outubro de 2006. Dispõe sobre Plano Diretor, o sistema e o processo de planejamento e gestão do desenvolvimento e ordenamento do Município de Salinas. Salinas, Câmara Municipal, 2006, $66 \mathrm{p}$.

SÃO FRANCISCO, Prefeitura Municipal. Lei oㅡ 2186 de 17 de Dezembro de 2004. Dispõe sobre Plano Diretor Estratégico, o sistema e o processo de planejamento e gestão do desenvolvimento urbano do Município de São Francisco. São Francisco, Câmara Municipal, 2004, 66 p. 
SOUZA, Marcelo Lopes de. Mudar a cidade: uma introdução crítica ao planejamento e à gestão urbanos. Rio de Janeiro: Bertrand Brasil, 2008.

VAINER, Carlos Bernardo. As escalas do poder e o poder das escalas: o que pode o poder local? In: Planejamento e Território: ensaios sobre a desigualdade. Rio de Janeiro: Cadernos IPPUR-UFRJ 2001-2/2002-1, DP\&A Editora. p. 13-32.

VILLAÇA, Flávio. As ilusões do Plano Diretor. São Paulo, Edição do autor, 2005. 